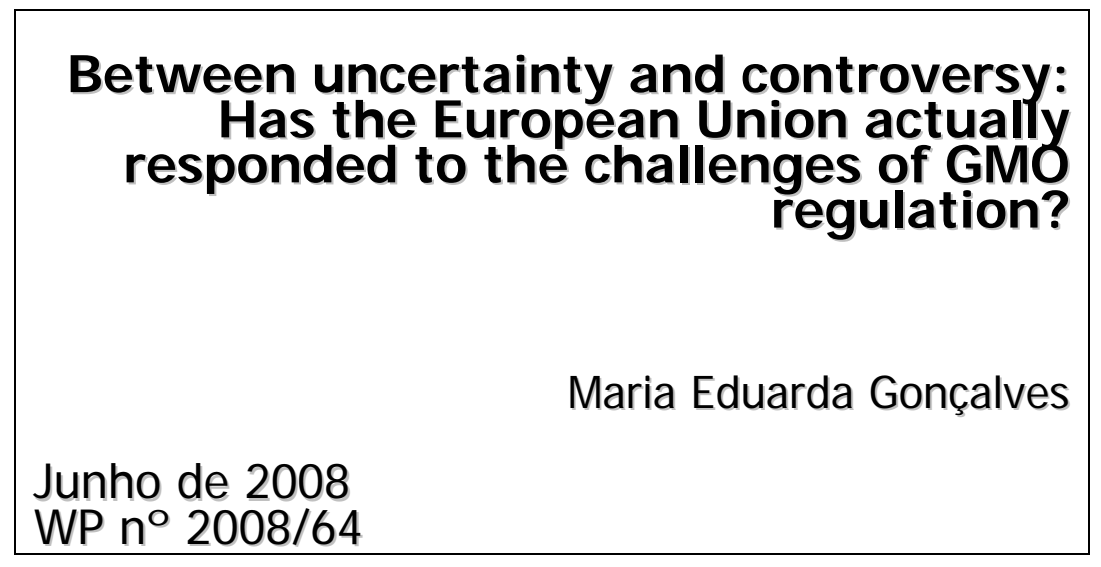

DOCUMENTO DE TRABALHO

WORKI NG PAPER
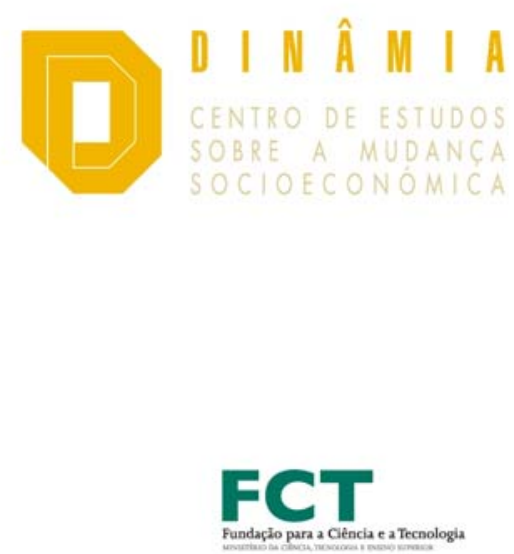
Maria Eduarda Gonçalves ${ }^{1}$

WP n $2008 / 64^{2}$

J unho de 2008

Abstract

1. INTRODUCTION

\footnotetext{
${ }^{1}$ Instituto Superior de Ciências do Trabalho e da Empresa - Secção Autónoma de Direito and Dinâmia Centro de Estudos sobre a Mudança Socioeconómica, Avenida das Forcas Armadas, 1649-026 Lisboa, Portugal, Phone: +351 217903494 - ext. 792141 Fax: 00351217940042 - E-mail: mebg@iscte.pt

${ }^{2}$ Research for this paper was undertaken as part of a research project, "Risk, Regulation and Citizenship in a Constitutional Europe", funded by the Fundação para a Ciência e Tecnologia (POCI/J UR/58859/2004).
} 


\section{Between uncertainty and controversy: Has the European Union actually responded to the challenges of GMO regulation?}

\section{Abstract}

The legal regime applicable to Genetically Modified Organisms (GMOs) in the European Union is an important witness to the central position assumed by risk in European regulatory and institutional reform over the last years. At the European level, the GMO regime provides an archetypical response by the regulator to the challenges raised by scientific uncertainty, social controversy and the weakening of national frontiers.

The need to act in situations where knowledge about relevant facts is insufficient or uncertain presents a test to the regulator and more generally to a legal system in which the verification or proof of the truth has traditionally been the requirement for both activating the law and for determining their possible violation. The precautionary principle provides the primary EU response to this challenge. Its inclusion in EU legislation on GMOs entails the recognition of the actual lack of conclusive evidence of harm which may be caused by the experimental use, the cultivation or industrial application of GMOs. At the same time, the extent of the public controversy surrounding this biotechnology led the EU to reconsider and possibly reinforce mechanisms for involving the civil society in the regulatory process. Yet, at the end of the day, the GMO regime structures the whole system for the assessment and management of the risk on the use of science and scientific opinions.

This article seeks to examine this apparent paradox and the way in which the GMO regime attempts to resolve it. This analysis will lead us in the end to questioning whether by meeting the risk raised by the development and use of GMOs in the way it does, the EU is not generating a sort of regulatory failure.

Keywords: risk regulation; GMO; European Union; precaution; science. 


\section{INTRODUCTION}

Global climatic change, the accumulation of hazardous industrial waste, contaminated foodstuffs, new diseases like AIDS or BSE, high voltage electricity transmission grids, genetically modified organisms ... In some sense the omnipresence of risk in contemporary society shows the flip side of its progress. Directly or indirectly associated with technological and industrial development, new risks are a matter for particular concern in a society which, paradoxically, has never been so safe.

Present anxiety about environmental, health and food risks is largely the result of the uncertainty and complexity which characterise them: the effects of risk are almost always difficult to predict and calculate. There is often insufficient knowledge of the factors that cause risk, as well as the conditions or moments which may lead to effective damages. Furthermore, these tend to be dispersed and are consequently difficult to control. Risk transcends the limits of traditional authority: it is either global, as in the case of the impact of climate change, or comes from a local source (like food risk or the risk of catching certain diseases) and it is propagated by people's mobility, commercial trade and the transfer of technologies.

Risk has a tendency to provoke discussion and controversy for all of these reasons. Scientific and technical uncertainties, conflicts of interest, economic, ethical and social implications, public sensitivity and extensive media coverage converge to turn new risks into a highly politicised issue. According to the theorists of risk society, risks are "politically reflexive" precisely because they contain the ingredients for a crisis of the political-administrative system and prevailing normative models while, at the same time, also shake up the convictions rooted in this model, particularly convictions about the objectivity and neutrality of science, the intrinsic goodness of technology or the infallibility of administrative decision-making. Risks politicise both industrial and technological production processes at the same time and force us to rethink the way they are regulated (Adam et al. 2000; Beck 1992).

Risk regulation is now a topical subject. I take risk regulation to mean the intervention of the public authorities in the market or in the economic and social processes to control their potentially adverse consequences for public health, the environment or the general safety of people and property. Over the last few decades, the affirmation of the regulatory paradigm for public action seems to have been influenced by the introduction of risk into the social and political agenda. It is a fact that the emphasis on regulation (along with the setting up of new types of public entities, the regulatory agencies) reflects a new stage in the role of the State, propelled by policy for the privatisation of

DINÂMIA - CENTRO DE ESTUdOS SOBRE A MUDANÇA SOCIOECONÓMICA 
public companies and the liberalisation of the markets. The perception of new risks emerged in this context as an additional driving force for the growth of both the regulatory state and new modes of governance (Majone 1996; Black 2002; Black 2005). Political leaders are being forced to depend on a more extensive and complex support of structures and agents, and to negotiate their objectives and means of action with the very people they govern.

In reality, risk to the environment and public health is an area which favours the "invention" of legal principles and original institutions. While, on the one hand, the regulatory process has to incorporate specialised knowledge in these areas, on the other hand, there is accentuated social pressure to bring greater transparency and to guarantee more active participation in risk management by interested parties and civil society - and the pressure is all the more intense as the scientific uncertainties and controversies surrounding risk assessment become more noticeable. Furthermore, the transnational incidence of risk makes international co-operation, the action of competent international organisations and the clarification of their responsibilities in this area an imperative.

In the European continent, the European Union (EU) has increasingly favoured regulation (Majone 1996). In the 1990s European risk regulation was marked by "mad cow" disease. The outbreak of BSE caused controversy which had significant political ramifications both in the European Community and in several of its Member States. It was associated with a realisation that the lack of clear separation between the mission of experts (scientific researchers and advisors) and political decision-makers had a negative effect: politicians clearly manipulated scientific reports and used them as an argument for delaying the recognition of the danger of this disease and consequently the taking of measures to stop it spreading (Ansell and Vogel 2006; Van Zwanenberg and Millstone 2005).

Thus, the reform of the EU procedures for food regulation addressed the concern with guaranteeing a greater independence of the scientific advisory system, as well as the adoption of more transparent practices of the institutions. Three successive phases in the decision-making process for activities or products which present a potential risk to the environment or people's health were identified: risk assessment (based on science); risk management (or political-administrative decision-making) and communication of risk (within the assessment and management system and with the public). This differentiation was based on a concept laid down in the European Commission's Communication on the Precautionary Principle and in the White Paper on Food Safety (CEC 2000; CEC 1999). 
This reform also led the creation of a novel entity, the European Food Safety Authority. The main functions of EFSA are to issue scientific opinions to the Community, monitor risk and communicate it to the public. ${ }^{3}$

Against this background, the complex European regime applicable to Genetically Modified Organisms (GMOs) is an important witness to the central position assumed by risk in European regulatory and institutional reform over the last few years. This regulatory effort has been influenced by the debate and controversy surrounding biotechnologies which increased during the 1980s and 1990s in various European countries.

GMOs regulation undeniably presents a typical example of the consequences of uncertainty, controversy and the weakening of national frontiers in a rethinking of the rules and procedures for regulation. The need to act in a situation where knowledge about relevant facts is insufficient or uncertain is a considerable challenge for the regulator and more generally for a legal system in which the verification or proof of the facts has traditionally been the requirement for both activating the law and for determining their (possible) violation. At the same time, the extent and diversity of the controversy surrounding this biotechnology has brought European and Member States institutions together to reconsider mechanisms for involving civil society in the regulatory process. Furthermore, though the transnational implications of the trade in GMOs require close co-operation between Member States and international organisations like the EU and the World Trade Organisation, the variety of the economic interests, perceptions of risk and conflicting social pressures across Europe appear to make a consensus more difficult to achieve.

Against this backdrop, this article seeks to examine the way in which the EU regulatory system has responded to the complexity of this regulatory field and, in particular, to uncertainty in science for risk assessment, and to the need to weigh up factors that cannot be appraised using scientific or technical criteria, such as economic and social values. We will start by summarising the main principles and rules contained in EU regulations and directives on GMOs. In the end, the critical analysis of this regime will lead us to questioning whether by meeting the challenges raised by the development and use of GMOs in the way it does the EU is not generating a new sort of regulatory failure.

\section{THE MAIN PRINCIPLES OF THE EUROPEAN REGIME FOR GMOS}

\footnotetext{
${ }^{3}$ Article 22 of Regulation (EC) No. 178/2002 of the European Parliament and Council, of 28th January 2002, which determines the general principles and rules for food legislation, creates the European Authority for Food Safety and establishes procedures for the safety of foodstuffs, OJ L 31 of 1.2.2002, p. 1-24.
} 
Genetically Modified Organisms (GMOs) are microorganisms, plants or animals whose genetic material has been altered artificially by introducing new genes. The most common types of GMOs already marketed in Europe are derivatives of soya, maize, and of oils from different varieties of cotton and maize seeds, which have been developed to make them resistant to plagues of insects or tolerant to herbicides. Unlike what happens with other improvement methods, the application of this technology is subject to detailed regulation in the European Union (EU) today: laboratory research, the experimental release of GMOs, the placing of GMOs on the market for cultivation, importation or manufacture into industrial products, the placing of food and feed on the market which consist of or contain GMOs, are part of a complex and innovative European regime today.

The following EU legal instruments are presently in force in this area:

- Directive 90/219/EC, of the European Council, with the latest wording given by Directive 98/81/EC, which applies to research activities and industrial activities involving genetically modified organisms (e.g. viruses and bacteria) in confined conditions (e.g. in the laboratory) ${ }^{4}$;

- Directive No. 2001/18/EC of the European Parliament and Council, of 12th March 2001, on the deliberate release into the environment of genetically modified organisms (e.g. field trials) and marketing of GMOs for the purposes of cultivation, importation or manufacture into industrial products $^{5}$;

- Regulation (EC) No. 1829/2003 of the European Parliament and Council, of 22nd September 2003, on genetically modified food and feed ${ }^{6}$; and

- Regulation (EC) No. 1830/2003 of the European Parliament and Council, of 22nd September 2003, on the traceability and labeling of genetically modified organisms and the traceability of food and feed produced from genetically modified organisms. ${ }^{7}$

Moreover, Regulation No. 1946/2003 rules the transnational movement of genetically modified organisms, whether intentional or associated with the exportation of GMOs to third countries ${ }^{8}$.

\footnotetext{
${ }^{4}$ OJ L 330 de 5.12.1998.

${ }^{5}$ OJ L 106/1, 17.4.2001.

${ }^{6}$ OJ $L 268 / 1,18.10 .2003$.

${ }^{7}$ OJ L 268/24, 18.10.2003.

8 Regulation (EC) No. 1946/2003 of the European Parliament and Council, of 15th July 2003, on the transnational movement of genetically modified organisms, $0 J \mathrm{~L} 287 / 1,5.11 .2003$. This regulation lays down a common system for notification and information about transnational movements of GMOs and seeks to ensure the consistent implementation of the provisions of the Cartagena Protocol to achieve the conservation and sustainable use of biological diversity and prevent risk to human health. The EU is party to the Cartagena
} 
According to this legal framework, the confined use, experimental release or launching of GMOs or GM products on the market should obey to the following basic principles:

i) Prior authorisation by the competent authority;

ii) Risk assessment as a central component of the authorisation process; and

iii) The fulfilment of specific requirements for traceability and labelling in the case of GM products.

According to the legislation, the structuring of procedures for the regulation of GMO risk is based on the distinction between two phases: risk assessment and management. Risk assessment is the responsibility of the competent national authorities (and the respective scientific or technical advisory bodies) or the EFSA. Risk management is understood to be the decisions taken by the regulatory authority, and is the responsibility of the EU decision-making bodies: the European Council and the European Commission within its respective area of executive competence.

The separation of assessment as a technical process, and management as a political process, formally represents the recognition of the ultimately political nature of the decisions made about the risks associated with GMOs. As indicated above, this separation is incorporated into both political and legal discourse in theory. Yet, it does not seem to be quite so clear in practice, as it will be shown below.

Procedures for authorisation in the case of experimental release and release for cultivation, importation and transformation into industrial products are initiated by the competent authority of the Member State in whose territory the release should be made (Article 6, paragraphs 5 and 8 of Directive 2001/18/EC). The request by the interested entity, most often a company, should be accompanied by a technical dossier and an environmental risk assessment. The authority issues an opinion in the form of an assessment report. If its opinion is negative, the company may submit a fresh notification to the competent authority of another Member State. If this assessment is positive, the Member State sends the assessment report to the European Commission, which circulates it among the remaining Member States, who may make observations and objections. If there are no objections, the national authority which carried out the initial assessment authorises the product's entry into the market.

Protocol on Biosafety, annex to the Convention on Biological Diversity of the United Nations Environmental Programme (UNEP), in force since 11th September 2003. The protocol was incorporated into European legislation by Directive No. 2001/18/EC. 
If there are objections, the legislation foresees a phase of conciliation between Member States, the European Commission and the notifier. If objections remain, the Commission requests the opinion of the European Food Safety Authority (EFSA), after which the Commission initiates the process known as "commitology": the Commission presents a proposal for a decision to the competent regulatory committee which is composed of representatives from the Member States. If this Committee votes in favour by qualified majority, the Commission adopts the decision. If the Committee rejects it, the proposal is submitted to the Council of Ministers for its adoption or rejection by qualified majority. If the Council fails to reach an agreement within three months, the Commission adopts the decision - an imperative which suggests an absence of discretion. ${ }^{10}$

Two comments may be made about this mechanism. Firstly, it is based on the close articulation of the EU institutions with the administrative authorities of the Member States which, in the case of disagreement, refer the decision to the European Commission. Secondly, the mechanism appears to have been designed to prevent decision-making deadlocks. However, precisely because the issues in question are highly sensitive politically, the neglect of national concerns becomes even more problematic in circumstances where qualified majorities are not possible.

In reality, in numerous situations where the Council did not reach an agreement in due time (i.e. 30 days), the Commission, in the exercise of its powers, did proceed with the authorisation of GMOs, including those for use in food and feed, in the face of a divided Council of Ministers and a public opinion particularly concerned about this issue. For example, in August 2005, the European Commission approved the importation of a strain of genetically modified maize (MON863) from Monsanto for use in feed. Monsanto's request had not been supported by a majority in the Council of Environment Ministers of 24th June of that year: the majority of governments abstained or voted against it. In accordance with Directive 2001/18/EC, the final decision reverted to the European Commission which authorized the placing of MON863 in the internal market despite the opposition by the various governments. ${ }^{11}$

\footnotetext{
9 "Commitology" is defined as the process for adopting measures to implement EU legislative acts by the Commission, which is assisted in this process by an expert committee appointed by the Member States.

10 Decision of the European Council of 28th June 1999, which sets the rules for the way the European Commission exercises its competencies (1999/468/EC).

${ }^{11}$ Commission Decision of 8 August 2005 concerning the placing on the market, in accordance with Directive 2001/18/EC of the European Parliament and of the Council, of a maize product (Zea mays L., line MON 863) genetically modified for resistance to corn rootworm, OJ L 207/17, 25.8.2005. See also Press release: GMOs: Commission reaction on Council votes on safeguards and GM maize MON863, 24.06.2005, accessed at http://europa.eu/rapid/pressReleasesAction.do? reference $=\mid \mathrm{P} / 05 / 793 \&$ format $=H T M L \&$ aged $=1 \&$ language $=E N$

(27 J une 2008).
} 
While the regulation of the release of GMOs addresses concerns about the protection of the environment, the regulation of genetically modified food and feed is more sensitive to the need to protect consumers. Its main objective is "to ensure a high level of protection of human life and health, animal health and welfare, environment and consumer interests in relation to genetically modified food, while ensuring the effective functioning of the internal market" (Article 1 of Regulation 1829/2003). Under the terms of this regulation, "foodstuffs must not have adverse effects on human health, animal health or the environment”, "mislead the consumer", or "differ from the food which it is intended to replace to such an extent that its normal consumption would be nutritionally disadvantageous to the consumer" (Article 4, paragraph 1).

In contrast to the procedure regulating the deliberate release of GMOs and their placing on the market which actively involves the national authorities, the procedure for food and feed is centralised in the European Food Safety Authority (EFSA). The national authorities only receive requests from companies to authorise the introduction of transgenic foods and then refer them on to the EFSA. Applications should be accompanied by a risk assessment study and a plan for monitoring their effect on the environment.

Authorisation is granted on the basis of a single risk assessment carried out by the EFSA. The Commission may disagree with the EFSA's opinion, in which case it must justify its position. Here again the European Commission also makes the final decision or rather, manages the"risk" according to the procedures of commitology: the Member States work within the framework of the Standing Committee on the Food Chain and Animal Health (Articles 35 and 58 of Regulation No. 178/2002). The European Commission also makes the final decision to grant or refuse authorisation, if the Committee and the Council have not been able to decide by qualified majority within the fixed time limit. $^{12}$

The traceability of GMOs makes it possible to follow the product from their manufacture to their distribution to check whether labelling requirements are complied with, in order to control potential adverse effects on health and the environment and to remove them from the market should any unforeseen risks be detected. Labelling requirements aim to inform the consumer or user about the product, thereby enabling them to make an informed choice. Regulation No. 1830/2003, which establishes the requirements to be fulfilled in these areas, is applied to all GMOs authorised to circulate in the European market, be they food, seeds etc.

${ }^{12}$ Cf. Decision cited in footnote 9.

DINÂMIA - CENTRO DE ESTUdOS SOBRE A MUdANÇA SOCIOECONÓMICA

ISCTE, Av. das Forças Armadas, 1649-026 Lisboa, PORTUGAL

Tel. 217938638 Fax. 217940042 E-mail: dinamia@iscte.pt www.dinamia.iscte.pt 
However, starting from the assumption that it is practically impossible to manufacture products which are $100 \%$ pure, products are exempted from the obligations stipulated if they contain under $0.9 \%$ of traces of GMO traces, on the condition that this presence is adventitious or technically unavoidable, or rather, the producers have to show that they have taken the appropriate steps to prevent the presence of this material (Article 4, paragraphs 7 and 8). Also excluded are meat, milk or eggs obtained from animals which are fed or treated medically with GMO products. In addition, the presence of up to $0.5 \%$ of GMOs is accepted as long as the products have been assessed scientifically and shown to present no risk for the environment and health, though formal approval is still pending. According to the Commission's services,

“This exemption aims to resolve the problem faced by operators who want to avoid using GMOs, but find that their products still contain a low percentage of genetically modified material due to accidental or technically unavoidable contamination.” (CEC 2007).

It is also considered practically impossible to prevent the presence of GMOs in agricultural crops or in the handling, storage or transport of non-GMO products originating in EU or other countries, as is the case for other products. The EU indeed explicitly accepts the co-existence of different types of crops based on the principle of freedom of choice for both the consumer and the farmer. The "Guidelines for the development of national strategies and best practices to ensure the co-existence of genetically modified crops with conventional agriculture and organic farming” 13 are recommended to regulate this co-existence and, to a certain extent, to protect conventional and organic crops from possible contamination by GMOs. In this case, the EU option was to issue general guidelines, formally non-compulsory, which gives the Member States the authority to decide on the specific conditions and limits to be respected for the cultivation of GMOs. ${ }^{14}$

Though the term "contamination" may have a negative connotation, the recommendation does actually accept it within certain limits, while imposing no more than the tolerance thresholds

\footnotetext{
${ }^{13}$ Commission Recommendation of 23 July 2003 on guidelines for the development of national strategies and best practices to ensure the coexistence of genetically modified crops with conventional and organic farming (2003/556/EC), OJ L 189, 29.7.2003, p. 36-47 in http://europa.eu.int/comm/agriculture/publi/reports/coexistence2/guide_en.pdf.

${ }^{14} \mathrm{Cf}$. Communication from the Commission to the Council and the European Parliament, Report on the implementation of national measures on the coexistence of genetically modified crops with conventional and organic farming, COM (2006) 104 final, Brussels, 9.3.2006, http://ec.europa.eu/agriculture/coexistence/com104_en.pdf.
} 
stipulated. ${ }^{15}$ At the same time, the recommendation expresses a concern with ensuring that sufficient and cost-effective measures are taken. One foremost objective indeed appears to be to prevent excessive burdens on farmers who choose to cultivate transgenics.

In sum, the assumption is that possible impacts on the environment and health are upstream issues, or rather, that they have already been considered and resolved during the science-based risk assessment process for authorising the use of GMOs in farming.

\section{UNCERTAINTY AND PRECAUTION: TOWARDS A “REGULATED SCIENCE”}

The European legislator has responded to the persisting scientific uncertainties in this area with the precautionary principle. According to this principle, the environment and health should be given the benefit of the doubt when there is no conclusive proof as to the risk of serious and irreversible harm due to a certain activity or product. This principle is applied typically to cases where, despite the fact that a preliminary scientific study shows that it is legitimate to fear potentially dangerous effects of a phenomenon, product or process on the environment and on human and animal health or vegetation sanitation, the data available is insufficient and inconclusive and does not make it possible to determine risk with sufficient certainty (CEC 2000).

Contrary to the traditional emphasis on compensating for damage once the damage has been done, precaution attempts to anticipate dangers which are likely to have adverse or irreversible effects on the environment, health or human safety more generally. The precautionary principle consequently encourages the development of procedures which make the framing and regulation of risk possible. This contrasts with the prevention principle, which was prevalent until the 1990s. This principle assumes prior knowledge of the impacts of products or activities on the environment; it is based on certainties and proof, while decisions bases on the precautionary principle are taken even if there are still uncertainties about those impacts.

The precautionary principle was introduced into the European legal system by the Treaty of Maastricht (1992) (Article 174 - Environment Policy), and has been translated into different

${ }^{15}$ Point 2.1.4 of the "Guidelines".

DINÂMIA - CENTRO DE ESTUdOS SOBRE A MUDANÇA SOCIOECONÓMICA 
types of sectoral Community legislation since that time. One example is the legislation on GMOs. GMO risk management is guided by this principle (Article 1 of Directive No. 2001/18/EC). Regulation No. 1829/2003 makes no explicit reference to precaution, but is implicitly ruled by it, given the subsidiary applicability of Directive No. 2001/18/EC. In its turn, Regulation No. 1830/2003 subjects traceability to the precautionary principle (Whereas 3).

This principle thus not only guides the initial decision of the competent national or Community authority, but also the release or marketing of GMOs once they have been licensed ${ }^{16}$. If new information about unforeseen adverse effects becomes available after the notification or decision, the authorities must reassess the situation, and may require the modification of conditions for the deliberate release of GMOs or even suspend or terminate it (Article 8 of Directive No. 2001/18/EC). Member States may also provisionally prohibit or restrict the use and/or sale of GMOs or transgenic products in their territory, when new or additional information is made available after authorisation has been granted or a new assessment has been made of existing information based on new or additional scientific knowledge and shows that there are valid reasons for considering that they are a risk to the environment or to health (the "safeguard clause" foreseen in Article 23 of Directive No. 2001/18/EC). In this case, the Member States must base their measures on a new (scientific) risk assessment. The Commission makes the final decision once the competent scientific committee has been consulted.

It should be noted however, that the precautionary principle regulates the decision-making process, but does not determine the prohibition of GMOs when there is doubt as to their innocuous nature. According to the European Commission's Communication on the precautionary principle, "in some cases the correct response may be to do nothing or at least not to introduce a binding legal measure. If it decides to act, a vast range of initiatives is available, including binding legal measures, a research project or recommendation.” (CEC

16 In whereas 8, Directive No. 2001/18/EC declares that: "The precautionary principle has been taken into account for the drafting of this directive and must also be taken into account when implementing it." Article 4 (1) adds that "the Member States shall, in accordance with the precautionary principle, assure that all appropriate measures are taken to avoid adverse effects on human health and the environment which may arise from the deliberate release or the placing on the market of GMOs." Parts B and C describe procedures for notification and authorisation to be followed in each case. 
2000). Precaution effectively gives the competent authorities (Member States and European Commission) a wide margin of discretion for deciding on acceptable levels of risk.

The question to be asked is therefore: how is this power distributed and exercised?

In order to answer this question, first of all it should be noted that the definition of risk and, consequently, the prohibition or authorisation of GMO with or without conditions are based on the results of an assessment to be made by scientists and experts appointed for this purpose. Central to the use of precaution is therefore the scientific study of risk. This is really the decisive phase for the preliminary authorisation of GMOs. ${ }^{17}$ Risk monitoring is also supported by "systematic and independent research". Besides, the measures to be taken for the co-existence of crops must be reviewed as more "scientific and technical progress" is made: the Member States are invited by Recommendation 2003/556/EC to promote research in partnership with the interested parties on the best ways of ensuring that co-existence. ${ }^{18}$

In all, despite the structural division of the regulatory system into the (scientific) assessment of risk and the (political) decision to authorise GMOs (or not), the latter is sustained by the former. Scientific information and arguments dominate the regulatory process from the moment the decision is notified and follow the "life" of the GMOs, and of the crops and products which use them.

Here we find an apparent paradox in the system: though on the one hand it is based on the precautionary principle, which recognises the lack of conclusive evidence or proof of harm which may be caused by the cultivation or use of GMOs, or in other words, it recognises

\footnotetext{
17 In Annex II of Directive 2001/31/EC entitled "Principles applicable to environmental risk assessment" gives details of the principles and methodology to be followed in risk assessment.

${ }^{18}$ The Court of Justice has explicitly valued the role of science as a precautionary instrument, while at the same time accepting the importance to stimulate the continuous progress of scientific research in order to fill these gaps in knowledge. In one of its decisions concerning the BSE, the Court expressly affirmed the "need to scientifically increase the range of new information and measures to be taken and consequently the need to review this measure" ((Decision of 5th May 1998 - The Queen c. Ministry of Agriculture, Fisheries and Food, Commissioners of Customs \& Excise, ex parte National Farmers' Union, David Burnett and Sons Ltd, R. S. and E. Wright Ltd, Anglo Beef Processors Ltd, United Kingdom Genetics, Wyjac Calves Ltd, International Traders Ferry Ltd, MFP International Ltd, Interstate Truck Rental Ltd and Vian Exports Ltd. - Preliminary ruling procedure: High Court of J ustice, Queen's Bench Division - United Kingdom - Case C-157/96).
} 
scientific uncertainty, on the other hand it structures the whole system for the assessment and management of risk on the use of science and scientific opinions.

At the same time, it creates a strong challenge to the traditional legal model which is based on the verification and demonstration of the facts. Legal and regulatory institutions open up to the idea of uncertainty, formally accept it and incorporate it into their discourse. However, even under these circumstances, the legal and politico-administrative decision-making authorities still need to be solidly legitimated. Science continues to offer this solid legitimisation despite its recognised limitations politically and administratively within the context of risk assessment.

The solution for this dilemma between the certainties required by law and the uncertainties offered by science seems to be a "regulated" science at the end of the day. The recognition of uncertainties about the production and use of scientific knowledge for risk assessment has not prevented it from being taken into consideration for the regulatory process - in fact the opposite is the case. The precautionary principle may then be regarded as "a means of dealing with scientific uncertainty, not a way of rejecting science” (Cazala 2004).

In general, the reorganisation of food risk regulation at European level was also based on the conviction that the social credibility of the regulatory systems is only possible if the authorities can strengthen the authority of science and publicly guarantee its independence from economic and political interests. The system of scientific advice for consumer protection and health was consequently reformed extensively during the second half of the 1990s, when a Scientific Steering Committee and eight new scientific committees were created, with longer mandates, to substitute those already existing. These bodies functioned in a more transparent and open way. This process also led to the establishment of the European Food Safety Authority, which incorporates the structure of the European institutions for scientific advice on food quality and safety, and naturally includes genetically modified foods.

Within the GMO regime, the use of scientific opinion and the promotion of scientific research indeed became legally framed in a strict manner. This regulation is expressed in a 
series of obligations imposed either on the producers of GMOs or on the regulatory authorities, including:

i) The obligation to carry out scientific risk assessments;

ii) The obligation to promote "systematic and independent research" once GMOs have been authorised or placed on the market, and

iii) The requirement for Member States to present scientific grounds if they plan to invoke the safeguard clause.

The role of science and scientific advice throughout the GMO regulatory processes thereby opens the way to a continuous dialogue between administrative bodies and the world of science and leads them to judge in each particular circumstance whether the scientific data available is valid and sufficient for determining acceptable risk. This framework also means that a growing role is played by the courts in the examination of the scientific demonstration which will be used as the basis for political and administrative decision-making in this area and for appraising its suitability according to the data and knowledge available at each given moment. ${ }^{19}$ These phenomena represent a radical change from the traditional concept of science as a self-regulated and independent profession.

Furthermore, it is important to clarify what kind of scientific practice we are talking about in the context of GMO regulation: this is essentially scientific advice. This advice is given by experts and should be seen as separate to both the science used in the design of legislation and administrative regulations and from laboratory science (Jasanoff 1990). While the latter can theoretically identify its objectives and procedures on an independent basis, so-called “regulatory science” is developed to support legislative or regulatory decision-making and favours brevity and prediction. In its turn, scientific advice consists of issuing opinions supported by the knowledge provided by experts in response to requests from the political

19 For example, in a much discussed decision, the Court of the First Instance confirmed the legality of the Council regulation which applied the precautionary principle to prohibit the marketing of an additive used in animal feed. This prohibition was based on the assumption of a relationship between the use of this additive as a factor for growth in animals and man's resistance to certain antibiotics. The Court considered the risk to be "sufficiently documented by the scientific data available." (Decision of the Court of the First Instance (Third Section) of 11th September 2002, Pfizer Animal Health SA against the Council of the European Union, Case T13/99, Jurisprudence Collection 2002 page II-03305). 
authorities. It tends to comply with political imperatives and time constraints, and with more flexible requirements for proof. Though supported by scientific knowledge, the role of the experts is hybrid and they are unlikely to avoid bringing socio-political judgements into their assessment.

The regulatory framework for GMOs seems to ignore these differences and neglect the valuative dimension of any risk assessment exercise, accentuated as we have seen by the uncertainties inherent to them.

FROM PRECAUTION TO PUBLIC INVOLVEMENT: RESOLVING A REGULATORY FAILURE?

\begin{abstract}
"The reform of the food safety institutions following the panic created by BSE, tended to accentuate rather than resolve the controversy surrounding the institutional relationship between risk assessment (scientific assessment and advice) and risk management (normalisation and application of regulations)." (Ansell and Vogel 2006).
\end{abstract}

This comment suggests that the way the EU has reorganised food risk regulation, particularly with the creation of EFSA, has subverted the objectives declared at its genesis. This observation seems equally valid for the European regulation of GMOs. 
As we have seen, the strategy followed in this area was to focus on authorisation procedures based on risk assessment, in other words to take the politics out of intrinsically complex problems by delegating their solutions to experts. Yet, the public realisation of the uncertainties of science and of differences of opinion among experts has caused people to question their independence and impartiality. In fact, despite investment in the study of GMO impacts, there is still a great lack of knowledge about their implications on public health and the environment, particularly in the long term. Within the Council of Ministers divergences of position have been expressed among EU Member States with respect to specific genetically modified plant varieties or products, backed by conflicting scientific opinions of national scientific institutions or advisers provide evidence. The public is then led to ask even more questions when confronted with political rhetoric and practices which still adhere to outmoded notions of truth or proof. Furthermore, in addition to real risks there are perceived risks, or rather, a fear, particularly of the unknown, which tends to spread throughout the population (Slovic 2002).

GMOs are indeed a paradigmatic case of contested technology. According to the latest survey on "The Europeans and Biotechnology" by the Eurobarometer, though those taking part in the survey were receptive to the applications of biotechnology in the area of medicine (so-called "red biotechnology"), 58\% rejected their use for agriculture and food ("green biotechnology") (Gaskell 2006). This rejection has much to do with the dispute about transgenic food promoted in various countries by either farmers who work in conventional and organic farming or by consumer or environmental protection agencies (particularly in countries like Austria, Greece and France). Active conflicts of interest and opinion among farmers and producers, including multinational companies, consumer and environmental protection associations and political parties as to the pros and cons, costs and benefits, opportunities and risks of GMOs, plus controversies within the scientific community, have sharply underlined the importance of the choices to be made and the fact that the acceptability of risk is an essentially political issue. As we have seen, this acceptability depends not only on the assessment of what might happen if the foreseen dangers actually come to pass, but also the "kind of world we want to live in" (Lee 2005). For all of these reasons, the controversy surrounding genetic engineering was seen as a unique opportunity 
for democratising the decision-making processes. But has the EU meet up such expectations?

As Torgensen pointed out, "the difficulties surrounding GMOs have worsened precisely because debates, regulations and policies only focus on risk" (technically defined) and have "neglected other issues" (Torgensen 2004). The underlying assumption appears to be that genetic engineering and its applications are a good in themselves and it is only important to guarantee that they are safe. In this context, the attempts of the political powers to base their authority only on science (though recognizably in constant progress) run the "risk" of proving blind to the requirements of the regulation and management of new risks such as those associated with GMOs. In order to function efficiently, risk regulation regimes depend both on their reliance in the judgment of experts and in the opinion of laymen (Hood, Rothstein and Baldwin 2004).

In the case of GMOs, the European legislator has addressed the special concerns of the public by setting up information and communication mechanisms. But to what extent are these mechanisms helping to pave the way to more informed decisions which are more receptive to the interests and values in question and more socially welcome?

According to the European legislation on GMOs, the regulatory authorities (Member States or European Commission depending on the case) should keep the public informed as part of the authorisation procedure. This is what happens when GMOs are experimentally released or placed on the market (Articles 9 and 24 of Directive No. 2001/18/EC). The public may access the data available and the assessment reports, and present their comments within 30 days of their publication. The opinion of the competent authority on foodstuffs containing or consisting of GMOs should also be made public, and any person may present comments within 30 days (Article 6, paragraph 7, of Regulation $N^{\circ}$ 1829/2003). The public must also be informed of authorised releases or of the registered location of cultivated GMOs and the results of monitoring activities.

Yet, there are still considerable legal and political barriers to making decisions in this area on the basis of factors which go beyond scientific and technical analysis. The essentially technical nature of assessment reports and opinions and the limited time available for consultation, raise the doubt whether the involvement of interested parties and the general 
public actually means that they have any real influence over the decisions made. Some governments have admitted that most of the observations they receive are far too general to be taken into consideration.$^{20}$ Besides, the European Commission has given clear signs that it underestimates the importance of this type of consultation. The Commission rejected the possibility of adopting a compulsory instrument in this area, arguing that this would work against "the need to achieve timely political decisions", as well as "the expectations of citizens that the European institutions actually produce something substantial rather than concentrate on procedures". ${ }^{21}$ This attitude otherwise leads to the understanding expressed in the White Paper on Governance in which a rhetoric of openness is contradicted by a proclamation of the need for "better and "faster" regulation" and by an explicit concern with speeding up the decision-making processes (CEC 2001).

It is true that Regulation No. 1829/2003 stipulates that decisions about new transgenic foods must take into account not only scientific opinions, but also "other legitimate interests", and accepts the possibility of the Commission consulting ethical committees and specifically the European Group on Ethics in Science and New Technologies (Article 33). But this is in the end a group of "ethical experts" (Wynne et al. 2007). And here once again it is the experts who have to translate social sentiments.

The lack of a clear institutional framework as a vehicle for ethical, cultural or social sensibilities on this subject reduces the protection of people's interests to their quality as consumers, which is a central objective of the regulation applicable to food and feed. Consumers are protected by product labelling, which presumably allows consumers to make informed choices.

Labelling is obligatory for all food and feed (Regulation No. 1829/2003), as it is for other products consisting of or containing GMOs (Regulation No. 1830/2003), which has been considered to be extended to products in which GMOs have been used for their production. Excluded are those products which have been "produced with" GMOs such as meat or milk from cattle fed with nutrients which contain GMOs (Lee 2005). Neither is labelling

${ }^{20}$ Cf. Second Report of the Commission and Council on the experience of the Member States with GMOs placed on the market within the scope of Directive 2001/18/EC [SEC (2007) 274].

${ }^{21} \mathrm{Cf}$. Towards a reinforced culture of consultation and dialogue - general principles and minimal rules for the consultation of the interested parties by the Commission [COM (2002) 174]. 
obligatory for food or food ingredients containing up to $0.9 \%$ of genetically modified material as long as the presence of this material is "fortuitous" or "technically unavoidable" (Article 12, 4).

Besides the limited types of information made public, it can always be alleged that access to information in itself does not guarantee society any real power to influence GMO regulation. There is a second paradox in the system on this point. Public consultation takes place during the assessment stage and involves technical reports or opinions. The information included on labels for transgenic products is also usually transmitted in a specialised language. In addition to the difficulty for the common man to understand this information, the function of product labels or the explanations transmitted by entities like the EFSA (in its function as a communicator of risk) may be seen as a subtle way for the regulatory authorities to share the responsibility for risk management with the virtual consumer or user; or as Bauman correctly observed, as a "counterfactual privatisation of risk" (Bauman 1996).

Though in the last instance, choices which may have effects on the environment or on health (whether to acquire or use them, whether to run the risk) are delegated to the individual as consumer or user, any real power to influence important decision-making in this area still escapes them.

Instead of providing access to information and public consultation in the risk assessment phase, would it not be more appropriate to involve the public in the risk management phase, or rather, when the basic decisions are taken to either authorise or reject the release of GMOs into the environment or the placing transgenic products on the market? This is the right time to bring the "other legitimate interests" of ethical and cultural, economic and social considerations into play.

As we have seen, the separation of risk assessment from risk management aimed to both guarantee the independence of the experts and to clarify the political responsibility of governments and administrations. This separation expressed recognition of the essentially political nature of risk regulation. By making the authorisation of GMOs largely dependent on science and experts, the European regulator has challenged this orientation and has started off a movement towards depoliticising this area, which has worked against the effective democratisation of this controversial innovation. 
The difficulties for the regulation of GMOs are partly structural: the newness of the issues to be regulated, the lack of data and reliable information available, and in spite of that, the strict obedience of political leaders to scientific opinion, all compete together and make the problems of credibility and efficiency in this area of regulation more persistent. The latter are exacerbated by a global market dominated by a small number of multinational companies in the biotechnological sector, one that it is not easy control.

Further obstacles are created by differing policies between Member States of the EU. Though the main objective of European directives and regulations on GMOs is to bring together and harmonise national legislative, regulatory and administrative provisions, their application in the member countries is not homogeneous. Work to harmonise legislation and co-ordinate institutions comes into conflict with the different dynamics in the farming sector and of social movements and organisations. The Europeanization of scientific advice through EFSA has not prevented the internal authorities from assuming differing positions. One specific indication of these differences has been the invocation of the safeguard clause laid down in Article 23 of Directive 2001/18/EC. Since this directive came into force, some Member States have maintained temporary prohibitions of authorised GMOs. However, in none of these cases did the EFSA consider that these measures were justified due to lack of scientific proof, which led the Commission to ask the governments in question to lift the bans $^{22}$.

In view of the problems brought by the present regulatory framework for GMOs, it might make sense to follow one of two directions (or both):

i) To extend and reinforce mechanisms for risk management with a view to involve in an effective manner interested parties and the public at large in these mechanisms;

\footnotetext{
${ }^{22} \mathrm{Cf}$., With respect to a recent case involving Austria, see Decision of the Commission of 7 May 2008concerning the provisional prohibition of the use and sale in Austria of genetically modified maize (Zea mays L. line T25) pursuant to Directive 2001/18/EC of the European Parliament and of the Council (2008/470/EC), OJ 162/31, 21.6.2008; and the Press Release of the 2826th Session the Environment Council, Luxembourg, 30th October 2007, in http://europa.eu/rapid/pressReleasesAction.do?reference=PRES/07/247\&format=HTML\&aged=0\&language=P T\&guiLanguage=en.
} 
ii) To design forms of public involvement in the "co-production", that is the construction, control and validation, of scientific and expert knowledge used in risk assessment (as suggested by Nowotny et al. 2001); and

iii) To rethink the now dominant concept of risk underlying the GMO regulations and procedures taking it beyond ecological and consumer risk to the "risk" incurred when exercising basic rights such as the freedom to say yes or no to the manipulation of life, and the actual dignity of the individual (what Brownsword names "rights-related risks") (Brownsword 2005; Anderson 2004).

\section{CONCLUSION}

The regulation of GMOs by the European Union addresses a particularly complex issue in view of the scientific uncertainties and the social controversies which involve this biotechnology, as well as the transnational nature of its production and uses. This article sought to examine the way in which the EU regulatory system has responded to the special complexity of this regulatory field and, in particular, to uncertainty in science for risk assessment, and to the need to weigh up factors that cannot be appraised using scientific or technical criteria, such as economic and social values.

The strategy followed was to focus on authorisation procedures based on risk assessment. Risk assessment relies primarily on the work and advice of scientific experts, which the EU recent reform has in part Europeanized through the restructuring of its scientific advisory committees and the creation of EFSA. However, the public acknowledgment of uncertainties of science and disagreements among experts, as well as differing policies of EU Member States (related in part to the specific features of the agriculture sectors) have underlined the importance of the choices to be made whenever a novel genetically modified plant variety or product is submitted for authorisation, and the fact that the acceptability of risk is an essentially political issue. For all of these reasons, the controversy surrounding genetic engineering was seen as a unique opportunity for democratising the decision-making processes.

Yet, the EU does not appear to have met up this expectation due to excessive reliance on sciencebased safety tests to the detriment of the relevant social and economic values at stake. While the 
separation of risk assessment from risk management aimed to both guarantee the independence of the experts and to clarify the political responsibility of governments and administrations, by making the authorisation of GMOs largely dependent on science and experts the European regulator started off a contradictory movement for taking politics out of the process, which has worked against the effective democratisation of this controversial innovation.

Thus the real challenge appears to be that of converting the system for the regulation of GMOs from a system principally based on expertise into a system also founded on values (Steele 2005). But for this to happen, concepts like that of risk and ideas deeply rooted in the world of law and regulation like the idea that innovation is a good in itself will have to be revised.

\section{REFERENCES}

ADAM, B., Beck U and Van Loon, J (2000), Risk Society and Beyond. London, Sage.

ANDERSON, P.N. (2004), "What rights are eclipsed when risk is defined by corporatism? Governance and GM food”. Theory, Culture \& Society, 21, 155-169.

ANSELL, C. Vogel D (2006), “The contested governance of European food safety regulation” in

Christopher Ansell and David Vogel (eds.), What's the Beef? The Contested Governance of European Food Safety, pp. 3-32. Cambridge/London, The MIT Press.

BAUMAN, Z. (1996) Postmodern Ethics. Oxford, Blackwell Publishers.

BECK, U. (1992) Risk Society. Towards a New Modernity. London, Sage.

BLACK, J. (2002) Critical reflections on regulation. London, LSE/Carr (Working paper).

BLACK, J. Lodge M, Thatcher M (eds.) (2005) Regulatory Innovation. A Comparative Analysis.

CHELTENHAM/UK, Northampton/USA, Edward Elgar.

DINÂMIA - CENTRO DE ESTUdOS SOBRE A MUDANÇA SOCIOECONÓMICA 
BROWNSWORD, R. (2005) "Biotechnology and rights: Where are we coming from and where are we going?” In: Mathias Klang and Andrew Murray (eds.) Human Rights in the Digital Age, pp 219-234. The Glass House Press.

CAZALA, J. (2004) "Food safety and the precautionary principle: the legitimate moderation of Community Courts”. European Law Journal, 10, 539-554.

CEC, Commission of the European Communities (2000) Communication of the Commission on the use of the precautionary principle. COM (2000) 1 final.

CEC, Commission of the European Communities (2001) European Governance. A White Paper. http://eur-lex.europa.eu/LexUriServ/site/pt/com/2001/com2001_0428en01.pdf.

CEC, Commission of the European Communities (1999) White Paper on Food Safety. http://eurlex.europa.eu/LexUriServ/site/en/com/1999/com1999 0719pt01.pdf.

GASKELL, G. et. al. (2006) Europeans and Biotechnology in 2005: Patterns and Trends, Eurobarometer 64.3, May. http://www.ec.europa.eu/research/press/2006/pdf/pr1906_eb_64_3_final_report-may2006_en.pdf.

HOOD, C. Rothstein H, Baldwin, R (2004) The Government of Risk: Understanding Risk Regulation Regimes. Oxford, Oxford University Press.

JASANOFF, S. (1990) The Fifth Branch. Science Advisers as Policy-makers. Cambridge, Mass., Harvard University Press.

LEE, M. (2005) EU Environmental Law. Challenges, Change and Decision-Making, Oxford and Portland/Oregon, Hart Publishing.

MAJONE , G. (1996) Regulating Europe, London, Routledge.

NOIVILLE, C. (2003) Du Bon Gouvernement des Risques. Paris, Presses Universitaires de France. 
NOWOTNY, H, Scott P, Gibbons M (2001) Re-Thinking Science: Knowledge and the Public in an Age of Uncertainty, London, Polity Press.

STEELE, J. (2004) Risk and Legal Theory. Oxford and Portland/ Oregon, Hart Publishing.

ROTHSTEIN, H. (2002) Precautionary bans or sacrificial lambs? Risk regulation and the reform of the UK food safety regime, ESRC Centre for Analysis of Risk and Regulation, Discussion Paper No. 15. London School of Economics and Political Science, London.

SLOVIC, P. (2002) The Perception of Risk, Londres, Earthscan.

TORGENSEN, H. (2004). "The real and perceived risks of genetically modified organisms”, EMBO Reports 5, Suppl 1 S17-S21.

http://www.nature.com/embor/journal/v5/n1s/full/7400231.html.

VAN, Zwanenberg P, Millstone E. (2005) BSE. Risk, Science and Governance, USA, Oxford University Press.

WYNNE, B. et al. (2007), Taking Knowledge Society Seriously. Report of the Expert Group on Science and Governance, Brussels, European Commission. 